\title{
INFLUENCE OF GLASS FIBRES TO VOLUME CHANGES IN CEMENT COMPOSITES
}

\author{
Ing. Valéria Gregorová; Ing. Zuzana Štefunková, Ph.D.
}

\begin{abstract}
The paper deals with verifying the influence of glass fibres to volume changes in cement composites, especially shrinkage. The tests were conducted with different doses of glass fibres on the prism samples with size of $40 \times 40 \times 160 \mathrm{~mm}$, which were fitted with glass contacts at their ends. The cement paste was modified by glass fibres in amount $0,1,2,3,4$ and $5 \%$ by weight of cement (replacement of cement). The effect of glass fibres on the bulk density, consistency, shrinkage and weight change was investigated. The achieved results have shown a positive effect of glass fibres on the shrinkage of cement composites, especially in the first days of measurement. The most significant impact was reflected in the higher dose of glass fibres -4 and $5 \%$.
\end{abstract}

Key words: Alkali resistant glass fibre, Cem-FIL, shrinkage

\section{INTRODUCTION}

Fibre concrete is special type of structural concrete. They are produced by adding suitable fibres to the basic components that acting as scattered reinforcement. Even distribution of the fibres in the structure of cement composites can significantly affect their properties, typically considered deficient. It is mainly the ability to better withstand the volume changes due to shrinkage and exposure to ambient temperatures not only during hardening of fresh composites, but using the appropriate fibre and after hardening [5].

Fibres with high fineness and relatively low modulus of elasticity are used to eliminate the formation and development of the number of shrinkage cracks at an early stage of hydration. The module of elasticity of fibre has to be higher than the module of elasticity of the hardened cement matrix. In this case, the cement matrix is very even reinforced with a large number of fibres. The admixture of such fibres does not substantially affect the physical properties of the hardened composites. The most used type of fibres is some polypropylene and glass fibres $[1,4]$.

Glass in the form of continuous fibre has properties that make it ideal as a highly preferred reinforcement. History of applications glass fibres is relatively young because they were not available suitable type's sources of alkali-resistant glass fibres useful in concrete. The glass fibres, which were in the beginning used into the cement composites, were disrupted by alkali in the pore solution of cement stone. Composites made from these fibres had not in consequence of degradation of the fibres the required durability.

Nowadays, the fibres glass as the reinforcement of concrete are produced of glass resistant to the effects of alkali. Their development began in England and Spain in the 60s of the last century. It was found that the content of $\mathrm{ZrO}_{2}$ in the glass fibre has a positive effect on the resistance to alkali. At first, the fibre contained $16 \%$ of $\mathrm{ZrO}_{2}$, the dose is gradually increased the up to $20 \%$. The alkali-resistant fibres are suitable for producing of various types of cement composites with a wide application in the building industry [6].

Resistance to alkali glass fibres is measured with special tests (SIC Strand in Cement). The result of the test is tensile strength of fibres after exposure in the alkaline environment of cement bodies in 
water at high temperatures. Standard glass fibre of type E (Eutal) is in environment of cement matrix attacked and very quickly loses the ability to reinforce [2].

The glass fibres (ARGF) with length of up to $35 \mathrm{~mm}$ can be used to shot cement composites (mainly thin-walled products such as facing panels, window sills, cornices, sewage pipes, columns). Composites (premix) with a fibres length of up $25 \mathrm{~mm}$ (usually up $12 \mathrm{~mm}$ ) are mixed in a mixer to plain cement concrete (large-sized, spatial elements with a smooth surface on both sides as a largescale prefabricated parts, containers, transformers, small garden architecture).

Alkali-resistant glass fibres can be used up to a dose of $5 \%$ by volume of the composite, without their aggregation occurred. The content of fibres in $1 \mathrm{~kg} / \mathrm{m}^{3}$ of the finished composite have an impact almost solely for preventing the formation shrinkage cracks during solidification. Fibres have the static function until at higher doses of fibres in the hardened composite. In this case, the fibres addition leads to improve the tensile strength and toughness of the concrete. They are resistant to oils, greases and acids [1].

Concrete reinforced with glass fibres acquires the residual strength. It is the ability to transfer the load even after crack formation. This allows the redistribution of stresses in concrete elements. Adding fibres in concrete substantially increases its parameters such e.g. toughness of concrete and fatigue resistance [3]

\section{EXPERIMENTAL METHODS}

Samples of cement composites were prepared from Portland cement CEM I 42.5 R. Drinking water supplied by the public water supply company was used on the mixtures. Alkali resistant glass fibres Cem-Fil ANTI-CRAK a length of $6 \mathrm{~mm}$ were used in amount $0,1,2,3,4$ and $5 \%$ by weight of cement (replacement of cement). Part of test samples was produced without additives as a reference samples. Samples were produced prism shape with size of 40 x 40 × $160 \mathrm{~mm}$, which were fitted with glass contacts at their ends.

In the production, it was important to determine the optimal water to cement ratio and procedure for mixing of the components of cement composites. Based on testing the consistency of cement pastes with different water to cement ratio on Heagermann flow table (Fig.1) was chosen a single water to cement ratio for all composites - W/C: 0.33. Using this factor was achieved generally good workability also on samples with the highest dose of fibreglass and the mixing water was not separated.

The glass fibres were manually mixed with cement. Cement composites were mixed from this mixture in a standard laboratory mixing according to STN EN 196-1 [7]. Consistency and bulk density was tested on a fresh cement pastes.

The fresh pastes were cast into moulds stored on a vibration table $(2$ minutes at frequency $75 \mathrm{~Hz})$. Moulds were cured for 24 hours in an environment with higher relative humidity ( $\varphi \geq 98 \%)$. After removing the samples from moulds was carried basic measurement on the Graf-Kaufman device. The next measurements were realized at the age of 2, 3, 4, 7, 14, 28, 56 and 91 days. During this measurement period samples were kept in laboratory environment (temperature $22 \pm 1{ }^{\circ} \mathrm{C}$, relative humidity $\varphi 62 \pm 2 \%$ ). At the same time and same period was pursued weight change. 


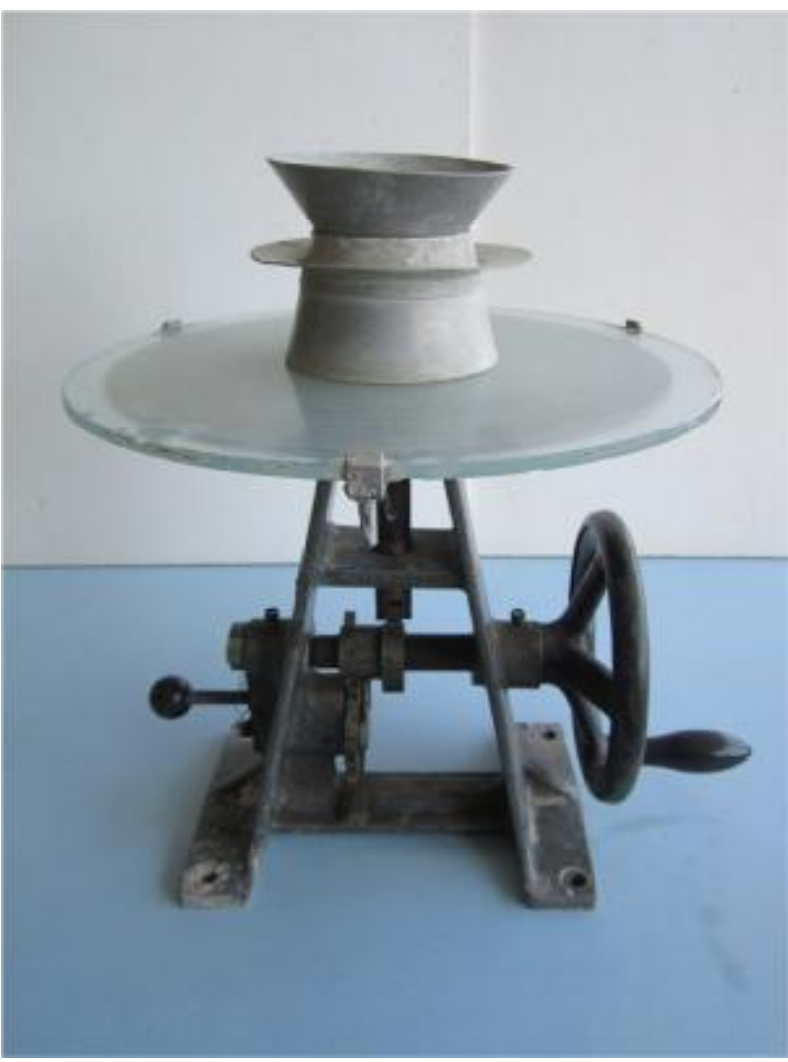

Fig. 1 Haegermann flow table

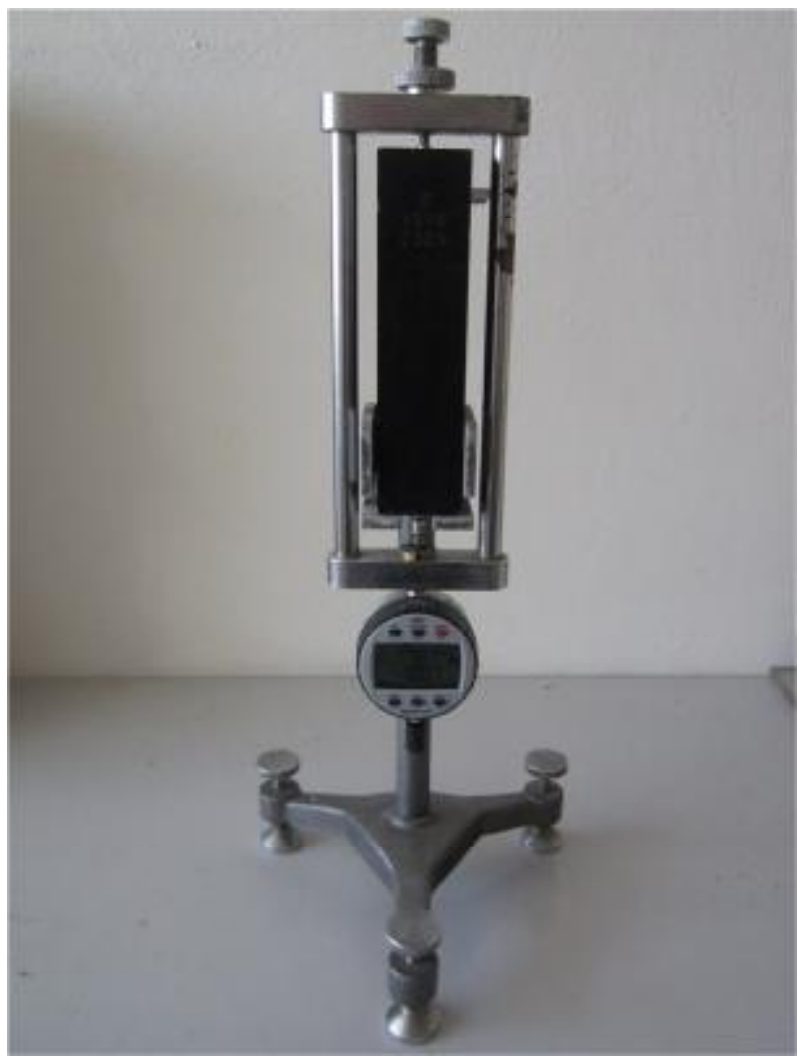

Fig. 2 Graf-Kaufman device

\section{RESULTS AND DISCUSION}

\subsection{Consistency}

Based on the above-mentioned work methods, water to cement ratio which would ensure good workability of the cement paste with different doses of glass fibre was studied. Optimal water to cement ratio was looking for by gradual reduction of water dosage. Using this optimal dose of water should have cement paste with $5 \%$ dosage of fibres a good workability.

Water to cement ratio -0.5 caused the fresh mortar was after spill thin and on the edges was the water separated from cement paste. Decreasing the dose of water led to less diameter of overflowing, but part of the water was still separated of cement paste. The suitable consistency was reached at a dose of $165 \mathrm{ml}$ per $500 \mathrm{~g}$ of cement (W/C: 0.33 ) and was characterized by good workability without separation the water of the cement paste. The same water to cement ratio was used in the production of the samples at a lower dose of fibres and samples without fibres. Decreasing the dose of fibres caused the mixture became more liquid. It also was led to increasing the diameter of the overflowing of cement paste.

\subsection{Bulk density of fresh cement paste}

The results of bulk density of fresh cement paste measurement are shown in Tab. 1 . The bulk density was decreased with increasing dose of glass fibres. 


\begin{tabular}{|c|c|c|c|c|}
\hline $\begin{array}{c}\text { Dose of fibre } \\
(\%)\end{array}$ & $\begin{array}{c}\text { Cement } \\
\text { (g) }\end{array}$ & $\begin{array}{l}\text { Water } \\
(\mathbf{m l})\end{array}$ & $\begin{array}{l}\text { Water to } \\
\text { cement ratio } \\
\text { (W/C) }\end{array}$ & $\begin{array}{c}\text { Bulk density } \\
\left(\mathrm{kg} / \mathrm{m}^{3}\right)\end{array}$ \\
\hline 0 & \multirow{6}{*}{1500} & \multirow{6}{*}{495} & \multirow{6}{*}{0.33} & 1958 \\
\hline 1 & & & & 1942 \\
\hline 2 & & & & 1940 \\
\hline 3 & & & & 1898 \\
\hline 4 & & & & 1885 \\
\hline 5 & & & & 1878 \\
\hline
\end{tabular}

Tab. 1 Bulk density of fresh cement paste

\subsection{Shrinkage of cement paste}

Based on the result, that are shown in Tab. 1 and in Fig. 3, it can be concluded that the impact of glass fibres is reflected especially in the first days of measurement when the samples with a higher content of glass fibres $(4.5 \%$ ) reached less shrinkage than samples with lower doses of glass fibre. Compared to the reference sample without the fibre, the shrinkage was less by $17 \%$ at a dosage of $4 \%$ glass fibres and about $21 \%$ at $5 \%$ fibre. During the next 7 days, this difference was lost and conversely, samples with a dose of $3 \%$ fibres reached higher shrinkage than the reference sample without the fibres. The effect of fibres on shrinkage of cement paste was again begun to show from 28 days. At first, the higher doses of fibres -4 and $5 \%$, and in 56 days also the lower doses of glass fibres. Test samples with fibres at the age of 91 days reached the less shrinkage than the reference sample without fibres. The most significant effect was reached by using the dosage of 4 and $5 \%$ fibres. The $4 \%$ dose of fibres caused reducing the shrinkage of $7 \%$ and $5 \%$ of the dose of $9 \%$ fibres.

\begin{tabular}{|c|c|c|c|c|c|c|}
\hline \multirow{2}{*}{$\begin{array}{c}\text { Age } \\
\text { samples } \\
\text { (days) }\end{array}$} & \multicolumn{7}{|c|}{ Dose of fibreglass (\%) } \\
\cline { 2 - 7 } & $\mathbf{0}$ & $\mathbf{1}$ & $\mathbf{2}$ & $\mathbf{3}$ & $\mathbf{4}$ & $\mathbf{5}$ \\
\hline $\mathbf{1}$ & 0 & 0 & 0 & 0 & 0 & 0 \\
\hline $\mathbf{2}$ & 0.3729 & 0.3736 & 0.3750 & 0.3813 & 0.3094 & 0.2947 \\
\hline $\mathbf{3}$ & 0.6177 & 0.6128 & 0.6104 & 0.6698 & 0.5313 & 0.5147 \\
\hline $\mathbf{4}$ & 0.7917 & 0.8421 & 0.8865 & 0.9219 & 0.7922 & 0.7841 \\
\hline $\mathbf{7}$ & 1.2177 & 1.2647 & 1.3396 & 1.4250 & 1.2750 & 1.2568 \\
\hline $\mathbf{1 4}$ & 1.6750 & 1.7249 & 1.7896 & 1.8823 & 1.7751 & 1.7111 \\
\hline $\mathbf{2 8}$ & 2.0958 & 2.1180 & 2.1396 & 2.1521 & 2.0609 & 2.0477 \\
\hline $\mathbf{5 6}$ & 2.4885 & 2.4568 & 2.4354 & 2.4781 & 2.4156 & 2.3745 \\
\hline $\mathbf{9 1}$ & 2.6281 & 2.5713 & 2.5271 & 2.5802 & 2.4438 & 2.4084 \\
\hline
\end{tabular}

Tab. 2 Shrinkage of cement paste $(\%)$ 


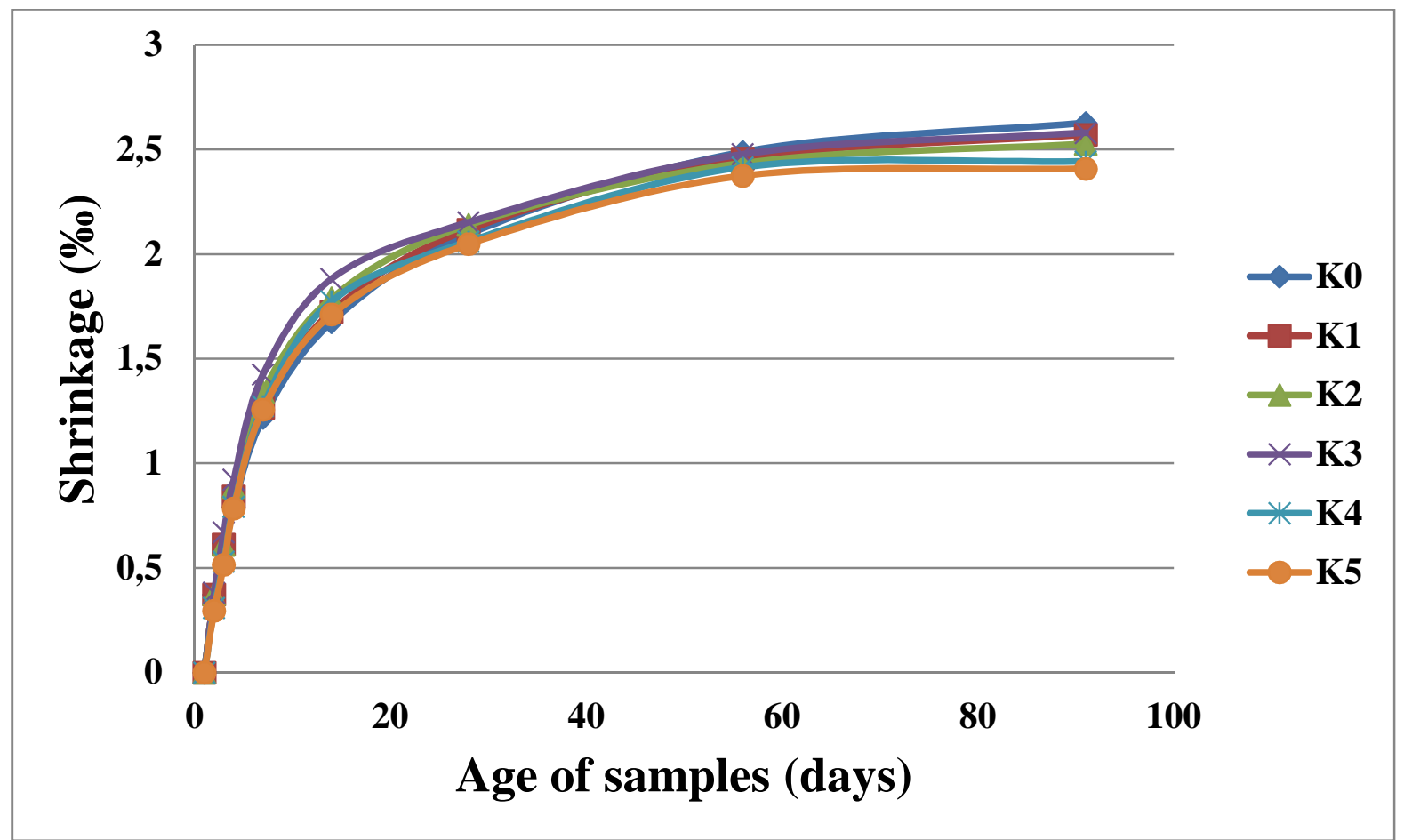

Fig. 3 Progress of shrinkage of hardened cement paste

\subsection{Weight change of cement paste}

The results of weight change of cement pastes are shown in Fig. 4. The different doses of glass fibre had no greater effect on weight change of cement pastes. The difference values weight change between test samples was in the range of one percent. A steady decrease in weight occurred in all samples. The decrease of weight was increased with increasing dose of fibres. The weight change reached at the age of 91 days values from 8.7 to $9.7 \%$.

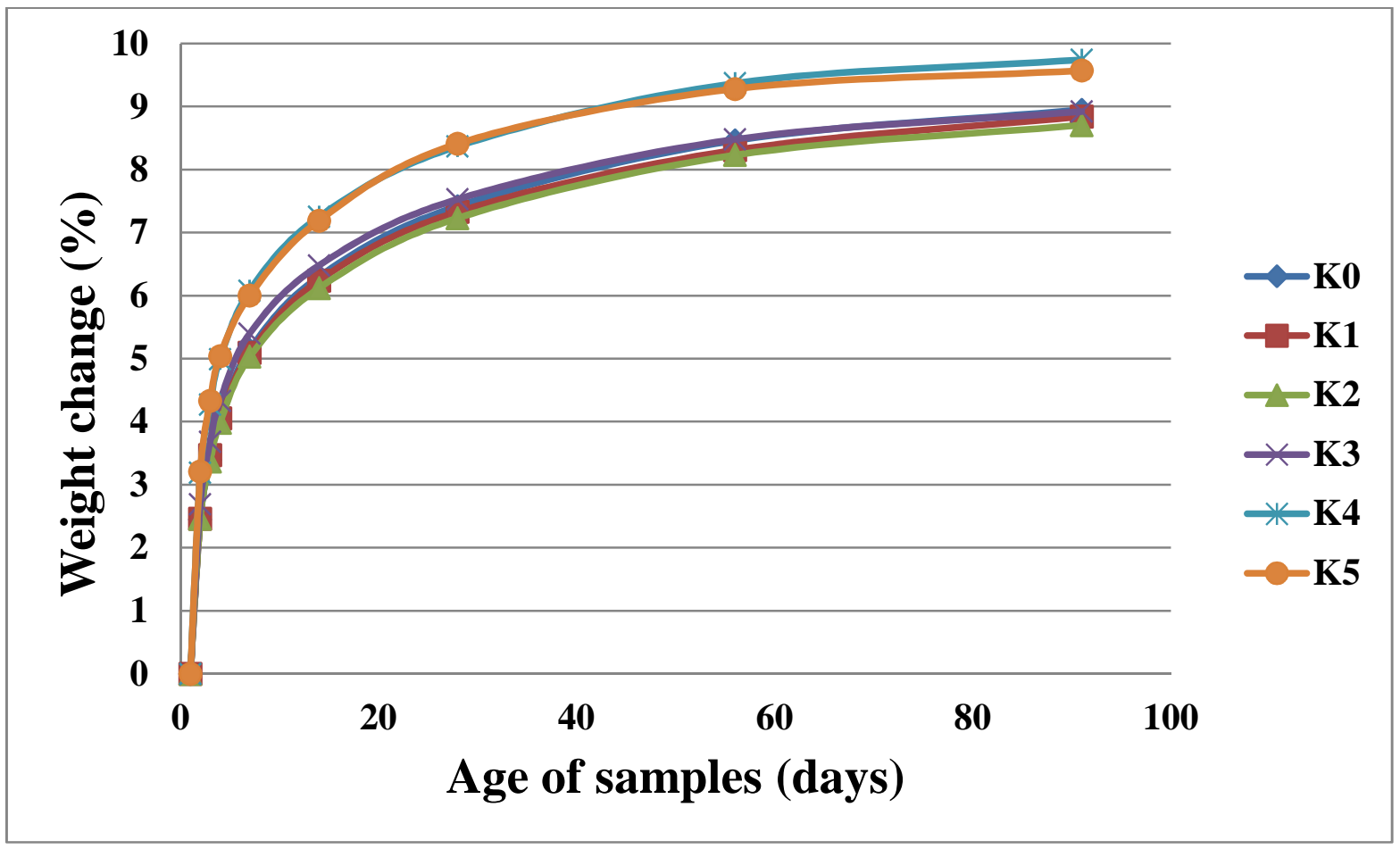

Fig. 4 Progress of weight change of hardened cement paste 


\section{CONCLUSIONS}

On the base of achieved results it can be concluded:

- The positive effect of glass fibres on the shrinkage of cement composites, especially in the first days of measurement. The most significant impact was reflected in the higher dose of glass fibres -4 and $5 \%$.

- The glass fibres dose has no significant impact on weight change. The weight of test samples was decreased with increasing dose of fibres.

- Consistency of fresh cement pastes worse with increasing content of fibres. It was demonstrated by reducing the diameter of the overflowing on the test flow table. Increasing dose of fibres was led to smaller diameter of the overflowing.

\section{Literature}

[1] Bajza, A. - Rouseková, I.: Technológia betónu. Bratislava: Jaga Group 2006, ISBN 80-8076032-2, s. 216

[2] Beneš, T.: Rozptýlená mikrovýztuž ze skleněných vláken. In: Beton TKS, roč. 2, 2002, č. 4, s. $31-33$.

[3] Beneš, T.: Sklocement Beneš, s.r.o. - kompetence ve vláknech do betonu. In: Beton TKS, roč. 4, 2004, č.5, s. 12-13.

[4] Mindess, S. - Bentur, A.: Fibre reinforced Cementitious Composites. London, Elsevier Applied Science 1990.

[5] Svoboda, L. a kol.: Stavebné materiály. Bratislava: Jaga group 2005, ISBN 80-8076-014-4, s. 244

[6] Takewaka, K. - Khin, M.: Deterioration and Stress-Rupture of FRP Rods in Alkaline Solution Simulating as Concrete Environment. $2^{\text {nd }}$ International Conference ACMBS-II, 11.-14.8.1996, Montreal (Quebec, Canada), pp. 649 - 656.

[7] STN EN 196-1(72 2110) Metódy skúšania cementu 